\title{
Ortho-subject-oriented approach to solving problems of positive socialization
}

\author{
Elena Petrova ${ }^{1, *}$, Victoria Dmitrieva $^{1}$, Vera Pchelinova $^{1}$, Alexander Ostrovskiy ${ }^{1}$, Tatiana \\ Vereitinova $^{1}$ \\ ${ }^{1}$ Russian State Social University, Wilhelm Pieck street, 4, build.1, 129226, Moscow, Russia
}

\begin{abstract}
The ortho-subject-oriented approach developed in this paper is aimed at combining the subject-oriented and orthobiotic approaches to personal and professional development. The applied aspect of orthobiosis is the ability to lead a diverse and active lifestyle, achieving the full cycle of human life. The purpose of applying the ortho-subject-oriented approach to vocational guidance is a holistic study of a person's vital activity, taking into account the interdependence of personal and professional performance. The sample of empirical research consisted of people aged from 14 to 58 years old $(\mathrm{N}=420)$, the clients of the Center for Psychological Counseling (located in Moscow), which provides occupational and vocational guidance and reorientation. The design of the research is based on understanding personal success as a system of dynamic relations between the external and internal world, determined by certain factors. The factor analysis of the data revealed the role of each factor in building images of the real and ideal situation in personal and professional development of the subject. The results of adopting an approach of personal and professional selfdetermination showed that $90 \%$ of clients are ready to participate in shortterm advisory training and only $10 \%$ are not ready to seriously engage themselves into the self-development activity. They are waiting for 'directive advice' from a consultant, thereby demonstrating dependency complex. The application of this approach makes it possible to conduct a self-study (positive self-rethinking) of one's resources in the process of vocational guidance, helping to build personal life path, and career growth in particular.
\end{abstract}

\section{Introduction}

The Ortho-Subject-oriented approach developed in this paper is aimed at combining the subject-oriented and orthobiotic approaches to personal and professional development. Ortobiotics is a scientific discipline about the art of leading a healthy lifestyle, of being in harmony with oneself, with one's inner and outer world. It is based on the conceptual guidelines on orthobiosisby Ilya I. Mechnikov, the Nobel Prize winner in the field of physiology and medicine (1908) [1]. The term 'orthobiosis' is derived from two Greek roots: 'ortho-' (from ancient Greek o $\rho$ ó $\varsigma$ - straight, regular) and 'bio-' (from ancient Greek ßíos life). The applied aspect of orthobiosis is the ability to lead a diverse, active and moderate

*Corresponding author: petrova-sorina@yandex.ru 
lifestyle, living the full cycle of human life into extreme old age. Orthobiosis, therefore, is a correct, long and happy cycle of an individual's life - the ontogenesis. Subjectivity is the highest level of conscious self-development, aimed at positivity and harmony in personal and professional spheres.

Such a person can make a truly independent and conscious choice of a professional path. In its turn, an individual has no more reliable support than participation in socially significant labor activity as the most important aspect of its positive socialization.

If we consider the socialization of man as a mutual action of two vectors: prosocial behavior and subjective well-being, then hypothetically we can get four possible outcomes. And the only outcome that can be considered as positive socialization is the one in which prosocial behavior (as the assimilation by a person of socially significant social roles, behavioral norms, cultural and historical traditions) coincides with the subjective satisfaction of a person with this activity [2]. One example of such a definition of positive socialization is the 'positive youth development' (PYD) concept, which is based on the theory of ecological systems. This concept turned out to be highly requested in terms of the development of youth programs, which set an objective not only to avoid any negative behavior, but also to achieve pronounced positive changes in youth behavior [3]. Also the model of ontopsychological pedagogy can be reckoned example of the up-to-date pattern of youth's positive development, which focuses on the development of a person's natural project and creativity through the responsible attitude of a person towards oneself, one's own professional activity, development of the culture of self-discovery and identity formation, ability to creative building of one's own life span and the highest level of professionalism [4].

The purpose of applying the ortho-subject-oriented approach to vocational guidance is a holistic study of a person's vital activity, taking into account the interdependence of personal and professional performance. In consultative sessions, a client learns self-analysis in order to prevent negative tendencies of his or her own development.

The basic concepts of the ortho-subject-oriented approach to the personal and professional development include the following. The development factor is the aggregate set of development conditions. Personality is understood as a system of dynamic relations between the external and the internal, the internal and the external world, determined by eight factors: parental family, reference group, mentoring, inclinations, abilities, level of aspirations, a model of the world of professions. In a generalized form, a human life cycle consists of the eight stages of the psychosocial development (Erik Erikson eight stages of psychological development [5]). The psychosocial stage of development is the stage of social maturity formation in the idea of personal achievement complex - the current group of behavioral manifestations, directed by partly or fully acknowledged mental structures. The era of professional development is a combination of its specific stages together with the stages of psychosocial development. The stage of professional development is an integral part of the era of professional development. In developmental psychology, it is customary to qualify psychological achievements in accordance with 'accumulation' of the physiological age duration. However, in reality, we are increasingly confronted with other phenomena advancing or delaying psychological development in relation to the physiological age.

In the context of a proper understanding of the development of social maturity of an individual, it is also necessary to differentiate the concept of a person's age.

Physical age is the duration of physiological (organismic) changes occurring from conception to the present (prenatal, or fetal period, plays an extremely important role in physiological development).

Biological age indicates an increase or decrease in the speed of organismic changes.

The passport (metric) age records the duration of life according to documents that may be inaccurate. 
The psychological age is diagnosed based on the observation of demonstrated complexes of personal achievements in relation to the moments or periods of the physiological age.

The positive development of the first year of life is evidenced by the basic trust complex; the complex of independence at the age of 3 ; the complex of skills or diligence in the period from 5 to 7 years old; the complex of accepting a social role by 11-13 years old; the complex of intimate and personal communication by the age of 17 to 23 ; the collectivism complex by the age of 25-40; the complex of creativity by the age of 45-60; the complex of satisfaction with the life lived by the period from 65 to 75 and older (Figure 1).

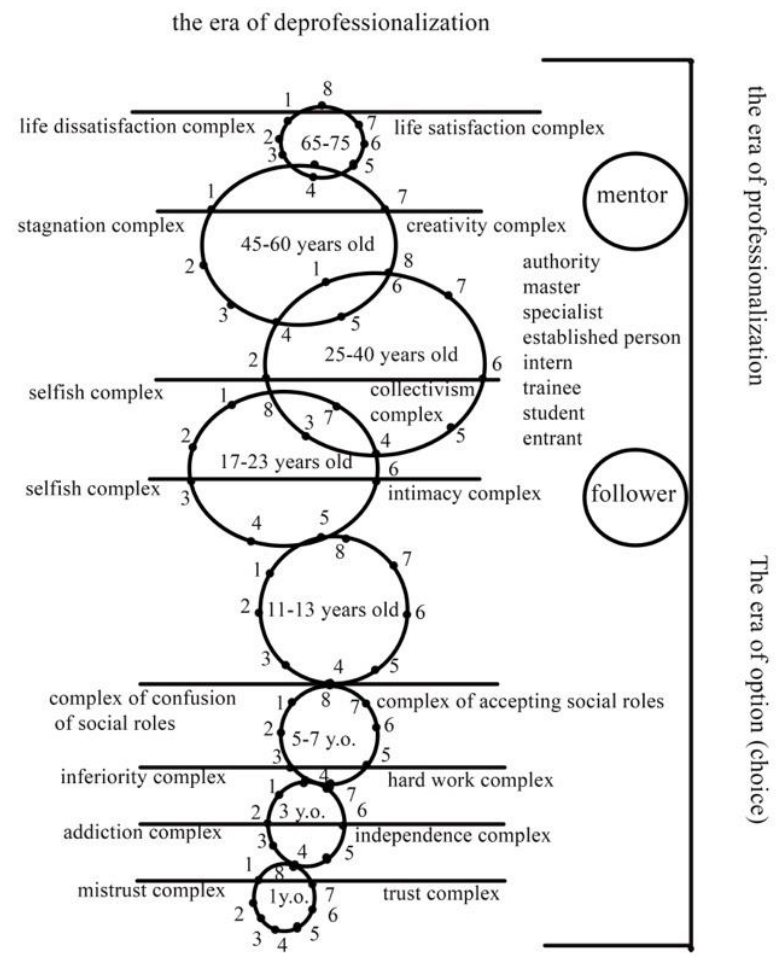

Fig. 1. Graphical view of the model of harmonious personal and professional development.

The result of professional identity formation is the willingness to take active guiding and executive steps at different stages of one's professional life: pre-professional training, the launch of one's career, professional development (alongside any steps involved in a career switch), the professional finishing line, meaning the end of one's career for one reason or another including reaching the retirement age. In each counselling case it is necessary to analyse this choice situation. Everyone proves to have quite a few participants like this in their life. These are members of one's own family, close relations who might replace one's parents, friends, teachers, and other people we meet during our lifetime. This structure is represented as a circle which symbolises the borders of consciousness of the subject of professional identity, while various factors are placed within the circle. To solve the problem, one needs to answer a multitude of questions and analyse this unique combination of conditions, that is the factors determining the situation of professional choice. It may either be at the launch of a professional career or at a point of professional development that the person seeking professional psychological help finds themselves. Figure 2 is a graphic structural representation of a situation of independent and conscious professional choice. Independence and awareness of the formation of professional projects are clear - the two 
vertices of the polygon represent the main professional project and a back-up professional plan. The person has become aware of various factors as of an arrangement of positions, and the result of this process is represented by a bunch of stretches from factor 8 to the rest of factors. We also observe a rationale for the professional project - the polygon has a stable octagonal base: all factors are interconnected as coordinated components of a choice situation. The borders of consciousness of the subject are open. Such a structure should be the result of completed career counselling at the $23^{\text {rd }}$ step. Referring to the graphic representation of a career choice situation and involved factors may be useful at the final stages in the context of consideration of career counselling and career advice hypotheses in terms of their understanding as of formulae for suitable careers. All career counselling steps shape the self-identification process, both in terms of the timescale and in terms of contents, therefore at the final stages the system can be described as open and stable.

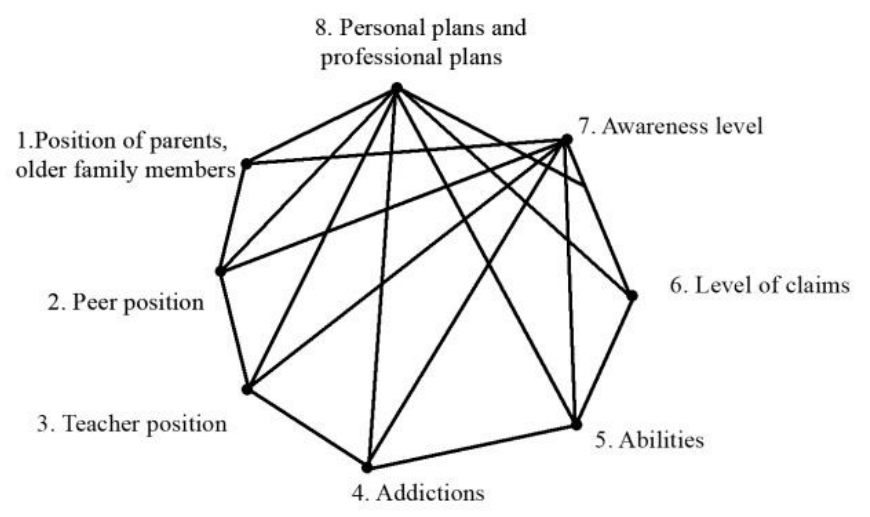

Fig. 2. Graphic image of the situation of independent and conscious professional choice.

Against the background of the stages of psychosocial development, three epochs of professional development unfold - the era of option (choice), the era of professionalization and the era of deprofessionalization (stagnation). The era of option includes the stages of infancy, early childhood, childhood and teenage. The epoch of professionalization consists of the following successive stages: 1) a stage that constitutes adherence to the image of an 'ideal' personality in a certain activity - the ego-state of a follower; 2) the stage of adherence to the 'ideal' image of an educational institution where 'ideal' professionals are brought up the ego-state of an entrant; 3 ) the stage of mastering professional activity at the initial stage - the ego-state of a student; 4) the stage of mastering professional activity at the final stage of training - the ego-state of a trainee; 5) the stage of integration into the real activity at its initial stage - the ego-state of an intern; 6) the stage of stabilization in the workplace in an institution - the ego-state of an established person; 7) the stage of mastering professional activity in a limited form - the ego-state of a specialist; 8) the stage of mastering professional activity in an expanded form - the ego-state of a master; 9) the stage of stable performance of professional activity without mistakes, better than others - the ego-state of authority, an expert; 10) the stage of transferring the skills and expertise to the new workers - the ego-state of a mentor. At the same time, this era covers such stages of personal development as adolescence, youth and maturity.

By success of an individual, we understand the mutual conjugation of physical and psychological age along with the stages of personal development and the eras of professional development. 
Modern psychodiagnostics, centered on personality individual traits, does not take into account its psychosocial core, the stages of its development as a subject of social life. The purpose of the Ortho-Subject-oriented approach to life and human activity is a scientific and practical study of personal and professional development, the specifics of passing through each stage of a person's development. Subsequently, the results of this study can be used to learn self-analysis of individual orthobiosis in order to prevent negative tendencies in one's development [6].

An important component of building a person's life path is choosing a profession [7]. The right choice of a profession is the basis of social orthobiosis. However, the history of international and Russian vocational guidance shows [8,9] that the dynamics of the development of modern vocational guidance systems are illustrated by a decrease in the age of those who come into guidance and their transition to the ego-state of an entrant without passing a follower stage, subsequently resulting in frustration with the profession at the established stage already. Nearly all vocational guidance at the individual level is aimed at identifying the factors of inclinations, aptitude [10,11], and claim as the main components of success nowadays $[12,13]$. The organization of vocational guidance process does not include the idea of social orthobiosis; common practice and technologies of this process suggest neither the ideas of holistic life construction, nor finding harmony between individuality and society, nor achieving a high level of professional and personal self-realization, nor turning to creativity as the pinnacle of professional growth and expertise $[14,15,16]$.

\section{Materials and Methods}

The sample of empirical research consisted of people aged from 14 to 58 years old $(\mathrm{N}=420)$, the clients of the Center for Psychological Counseling (located in Moscow), which provides occupational and vocational guidance and reorientation.

The study was conducted with the aim of introducing theoretical developments of the Ortho-Subject-oriented approach into the practice of vocational guidance and obtaining feedback from clients. The Ortho-Subject-oriented career guidance advisory model is based on a combination of theoretical views on personal development proposed by Merlin [17] and Erickson [18], as well as theoretical views on professional development, developed by Klimov [19]. Special procedures for informing and interviewing have been developed in order to transfer the Ortho-Subject-oriented knowledge from a psychologist to a client. The psychological and pedagogical engineering of consultative models of professional selfdetermination is based on the client's understanding of one's own position in terms of the different stages of personal and professional development in accordance with physical age. Engineering takes into account possible asynchronies of physical and psychological ages and an explanation of these circumstances to the client. Understanding of these circumstances by the client and propriate social environment or immediate community should lead to the full awareness of one's own situation. The design of the research is based on the principles of human consciousness and responsibility for decisions made and actions performed. In accordance with these principles, in the described approach, a person is understood as a system of dynamic relations between the external and internal world, determined at each stage of psychosocial development by eight factors: parental family, reference group, mentoring, inclinations, abilities, level of aspirations, a model of the world of professions (about 50 descriptions) [20]. The study design included 10 meetings once a week, each lasting 3 hours. Each factor was explained with the help of video materials and investigated using a special technique. To understand the influence of members of a client's parental family on his or her professional scenario, a genogram was built and analyzed. Understanding the role of the reference group members was achieved through the construction of a sociogram. The 
role of an authoritative person was revealed by constructing an objectogram. Inclinations and abilities were analyzed on the basis of chronogram compilation. The level of claims of public recognition was clarified with the help of constructing the development diagram (graphic display of correlation between factors, stages of personal development, eras and stages of becoming a professional). The model of the world of professions was built using the profession formulas [21].

The research hypothesis involved the assumption that the clients had a greater need for knowledge about the personal development and specifics of personal development in the context of professional development. However, in practice, the lack of information about the world of professions has been brought out to the forefront, which in turn influenced the structuring of the topics of consultations, without changing the essence of the consulting work.

\section{Results}

The results of adopting the Ortho-Subject-oriented approach at the level of advisory training for personal and professional self-identification showed that $90 \%$ of clients are willing to participate in such work (32-36 hours). $10 \%$ of clients, regardless of age, are not ready to seriously 'engage in themselves', to be involved in learning activities on self-analysis and analysis of the social world in relation to their own development situation. They are waiting for 'directive advice' from a consultant, thereby demonstrating the dependency complex characteristic of psychological age of early childhood, due to the lack of the independence complex. This group of clients requires much more time to work with.

During the first consultation session, each client answered an open-ended question that was presented in the wording: 'Personality in the profession is ...'. In total 4 groups of definitions came forth. Content analysis of the statements showed that $85 \%$ of clients are guided by everyday ideas while defining this notion of personality and did not particularly think about this concept. $10 \%$ of clients define the connection between personality and a profession through the concepts of inclinations and interests, $5 \%$ identified the motivational aspects. The remaining 5\% of clients gave non-informative definitions such as 'Personality in the profession is a person, ... a man ...', etc. Figure 3 shows quantitative distribution of these responses.

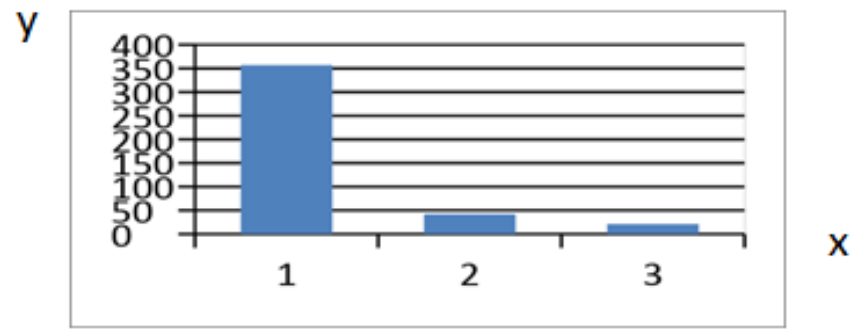

The X-axis :groups of definitions of personality

The Y-axis: number of respondents

Fig. 3. Quantitative distribution of clients' responses to the unfinished sentence 'Personality in the profession is ...'.

In Figure 3 the first group of definitions (1) includes "blurring" ideas about personality. The second group (2) reflects a kind of "approximation" to the characteristics of personality. The third group (3) contains possibility statements in the definition of personality that personal achievements are possible through professional activities. 
After completion of the counseling sessions, definitions of the concept of personality in a profession was distinguished by its informative, scientific, individual-semantic content.

In this article, we would like to note the features of professional self-determination of clients who had professional experience before contacting a consultant. After the counseling sessions, having learned about the factors of professional choice, the clients retrospectively recalled the answer to the question: 'What factor was crucial in the initial professional choice?' Figure 4 shows quantitative distribution of responses to this question. The first factor (1) reflects the answers of $35 \%$ of clients - their choice was determined by their parents' positions and opinions. The second factor (2) contains the answers of $22 \%$ of clients - their choice was influenced by their friends and peers. The third factor (3) included the clients that were influenced by their teachers and film characters ( $26 \%$ of the respondents). $8 \%$ of choices were explained by inclinations to favorite activities - the forth factor (4), and $6 \%$ of choices by personal abilities - fifth factor (5). Only $2 \%$ of the clients thought about glory and fame, sixth factor (6), while making professional choice. None of the 206 people mentioned the knowledge about the holistic model of the world of professions when they had to make a choice. Due to total ignorance of the fact that the world of professions is so vast, it was literally 'shocking' for the clients to learn about real quantitative and qualitative composition of the world of professions. Therefore, a person is faced with the problem that 'he or she did not know that he was not aware about this situation'. This fact extremely complicates the process of positive socialization of a person.

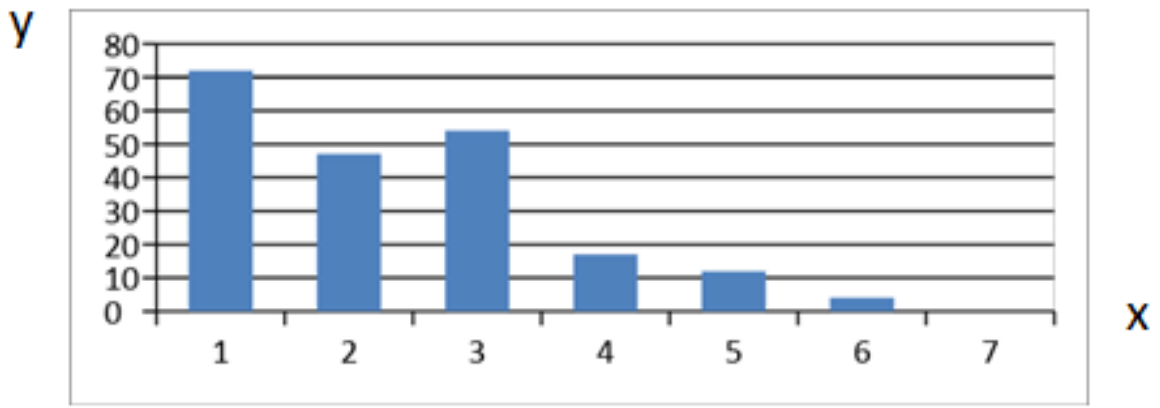

The X-axis: factors determining the situation of professional choice The Y-axis: number of respondents

Fig. 4. Quantitative distribution of clients' answers to the question: 'What factor was crucial in the initial professional choice?'.

As the counseling work was completed, the clients were asked: 'What factor is determining for you in the conscious, informed choice of professional career?

Figure 5 shows the quantitative distribution of responses of 402 clients. For $9 \%$ of clients this factor was the factor of a parental family - factor 1 . For 3\%, the most important is the position of the reference group (factor 2). $2 \%$ of responses reflect the importance of the mentoring - factor 3. $4 \%$ of clients mention the aptitude factor (4), 3\% -personal abilitiesfactor 5 . The level of claims is crucial in $18 \%$ of responses (factor 6 ). Finally, $74 \%$ of clients acknowledged the factor of being conscious about the holistic world of professions - as the most determining factor (7). 


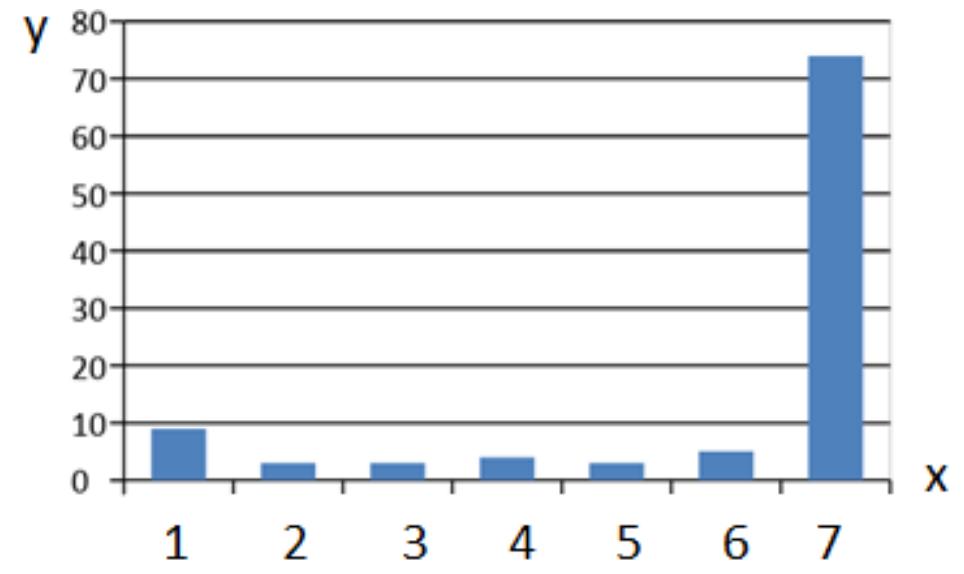

The X-axis: factors that make the situation of professional choice The Y-axis: the number of respondents

Fig. 5. Quantitative distribution of clients' answers to the question: 'What factor is determining for you in the conscious, informed choice of professional career?'.

\section{Discussion}

The practical significance of this research lies in the opportunity of developing specially targeted educational courses in the early stages of personal development and orientation in the holistic world of professions (starting from secondary school), as the knowledge about it is carried out since childhood in an inductive way, based on mundane and limited ideas. Holistic and generalized knowledge of the world of professions must be complemented by disciplines on self-knowledge and self-development which contribute to a person's positive socialization in society. The particular emphasis should be placed on the formation of skills for self-alignment of a person's own professional path.

Combination of the orthobiotic approach and the subject-oriented approach allows selfstudy of one's resources and formation in the process of vocational guidance of a subject for building one's life path in general, and career growth in particular. In fact, the most important factor in the conscious choice of a profession is understanding by trainees themselves of a role of work and a profession in one's life, the correlation of a life path, lifestyle, personal fulfilment and realization of all resources. In other words, well-built professional counseling stimulates a person to become a real subject of his working life.

The bottleneck in the independent choice of a suitable profession and an option of an educational institution is the lack of knowledge by the subject about choosing the main characteristics of the professions, the specifics of a person's life cycle, its internal laws and mechanisms that are aimed at developing the synthetic purpose of life; about the hidden opportunities and reserves of the mental development itself .

The determinants and conditions of development must be observed in connection with the classification of life periods in which ontogenetic and pedagogical approaches to stadial development are of equal importance. In this regard, it is necessary to use variable models of assistance in labor and professional self-determination, which are based on the specifics of deviations from the stadial psychological development. 


\section{Conclusions}

The described model is an unapparelled result, which has already demonstrated consistent efficiency in practical consulting work with adolescents and adults. And can be universally applicable in order to provide vocational guidance and the analysis of personal and professional development at any stage, in any type of work activity, as well as in the absence or loss of employment for various reasons. The advisory teaching practice used in this study requires organized professional training of psychologists-career advisors who possess communicative, professional and developmental competence.

\section{References}

1. I. Stambler, Advances in Gerontology 5(4), 201-208 (2015) DOI: https://doi.org/10.1134/S2079057015040219

2. I. Volkova, L. Skitnevskaya, E. Volkova, L. Tsvetkova, T. Vereitinova, V. Dmitrieva, Educational and School Psychology. International Journal of Psychology 51(S1), 448522 (2016) DOI: http://dx.doi.org/10.1002/ijop.12313

3. R. Pilkauskaite-Valickiene, Procedia - Social and Behavioral Sciences 197, 265-270 (2015) DOI: https//dx.doi.org/10.1016/j.sbspro.2015.07.134

4. A. Meneghetti, EPJ Web of Conferences 224, 06003 (2019) DOI: https://doi.org/10.1051/epjconf/201922406003

5. S.G. Zeren, Procedia - Social and Behavioral Sciences 46, 2445-2450 (2012) DOI: https://doi.org/10.1016/j.sbspro.2012.05.500

6. R.G. Craven, R.M. Ryan, J. Mooney, R.J. Vallerand, A. Dillon, F. Blacklock, N. Magson, Contemporary Educational Psychology 47, 32-43 (2016) DOI: https://doi.org/10.1016/j.cedpsych.2016.04.003

7. C. Vlaicu, C. Voicu, Procedia - Social and Behavioral Sciences 92, 1026-1032 (2013) DOI: https://doi.org/10.1016/j.sbspro.2013.08.794

8. M. Suditu, Procedia - Social and Behavioral Sciences 69, 1993-1997 (2012) DOI: https://doi.org/10.1016/j.sbspro.2012.12.155

9. M.E. Quiroga-Garza, D.L. Flores-Marín, R.R. Cantú-Hernández, I.E. Eraña Rojas, M.V. López Cabrera, Heliyon 6(4), e03860 (2020) DOI: https://doi.org/10.1016/j.heliyon.2020.e03860

10. O.B. Chesnokova, S.M. Churbanova, S.V. Molchanov, Cultural-Historical Psychology 15(4), 109-118 (2019) DOI: https://doi.org/10.17759/chp.2019150411.

11. E. Valitova, V. Starodubtsev, L. Goryanova, Procedia - Social and Behavioral Sciences 214, 739-747 (2015) DOI: https://doi.org/10.1016/j.sbspro.2015.11.706

12. O.V. Galustyan et al., TEM Journal 8(3), 1071 (2019) DOI: https://doi.org/10.18421/TEM83-53

13. V. Anghelache, Procedia - Social and Behavioral Sciences 187, 481-486 (2015) DOI: https://doi.org/10.1016/j.sbspro.2015.03.090

14. E.K. Kalymbetova, D.D. Duisenbekov, G.M. Arynbaeva, M.K. Zholdassova, L.O. Baimoldina, N.M. Sadykova, Procedia - Social and Behavioral Sciences 171, 263-267 (2015) DOI: https://doi.org/10.1016/j.sbspro.2015.01.120

15. E.V. Stakanova, E.A. Dzyuba, E.V. Tolstikhina, Procedia - Social and Behavioral Sciences 86, 494-497 (2013) DOI: https://doi.org/10.1016/j.sbspro.2013.08.603 
16. M.M. Basimov, N.I. Shulga, Scientific notes of the Russian State Social University 18, 15-24 (2019) ISSN: 2071-5323.24 DOI: http://doi.org/10.17922/2071-5323-2019-18-1$15-24$

17. A.Y. Kalugin, Perm University Herald. Series" Philosophy. Psychology. Sociology" 2, 252-263 (2018) DOI: http://doi.org/10.17072/2078-7898/2018-2-252-263

18. V. Gaete, Revista Chilena de Pediatría 86(6), 436-443 (2015) DOI: http://doi.org/10.1016/j.rchipe.2015.07.005

19. A.B. Leonova, O.G. Noskova, Moscow university psychology bulletin 14(2), 4-14 (2015) DOI: https://doi.org/10.11621/vsp.2015.04.04

20. Dictionary of Occupational Titles https://occupationalinfo.org

21. Atlas of new professions (M., 2014) http://www.skolkovo.ru/public/media/documents/research/sedec/SKOLKOVO_SEDeC _Atlas_2.0.pdf 